\title{
Anestesia Spinal Dosis Rendah untuk Seksio Sesarea pada Pasien Mitral Stenosis Berat
}

\author{
Nopian Hidayat ${ }^{1}$, Yusmein Uyun ${ }^{2}$, Dewi Yulianti Bisri ${ }^{3}$ \\ ${ }^{1}$ Departemen Anestesiologi \& Terapi Intensif Fakultas Kedokteran Universitas Riau-RSUD Arifin Achmad \\ Pekanbaru Riau, ${ }^{2}$ Departemen Anestesiologi \& Terapi Intensif Fakultas Kedokteran Universitas Gajah Mada- \\ RSUP Dr. Sardjito Yogyakarta, ${ }^{3}$ Departemen Anestesiologi \& Terapi Intensif Fakultas Kedokteran Universitas \\ Padjadjaran-RSUP Dr Hasan Sadikin Bandung
}

\begin{abstract}
Abstrak
Penyakit jantung pada kehamilan meningkatkan angka morbiditas dan mortalitas ibu dan janin. Mitral stenosis adalah lesi katup jantung yang paling sering didapatkan pada wanita hamil dan hampir selalu disebabkan oleh penyakit jantung rematik. Perubahan fisiologis yang terjadi selama kehamilan dan periode peripartum dapat memperburuk gejala dan derajat penyakit jantung. Akibatnya, banyak wanita pertama kali didiagnosis penyakit jantung selama kehamilan. Seorang wanita berusia 24 tahun gravida 32-33 minggu dengan kongesti gagal jantung fungsional kelas III, mitral stenosis berat, ejection fraction (EF) 59\%, regurgitasi trikuspid sedang, dan dilatasi atrium kiri menjalani seksio sesarea dengan anestesi spinal dosis rendah menggunakan bupivakaine 0,5\% hiperbarik 7,5 mg ditambah fentanyl 50 mcg secara intratekal. Blok sensoris dicapai setinggi torakal 6 dalam waktu 4 menit 20 detik. Hemodinamik pasien stabil selama operasi maupun pasca operasi. Tidak diperlukan pemberian vasopresor. Pasca operasi pasien dirawat di intensive care unit (ICU) selama 3 hari dengan hemodinamik yang stabil. Laporan ini menyoroti bahwa anestesi spinal dosis rendah dapat menjadi pilihan yang baik dalam manajemen anestesi untuk seksio sesarea yang disertai dengan mitral stenosis berat.
\end{abstract}

Kata kunci: mitral stenosis berat; spinal anestesi dosis rendah; seksio sesarea

\section{Low Dose Spinal Anesthesia for Cesarean Section with Severe Mitral Stenosis}

\begin{abstract}
Heart disease in pregnancy increases maternal and fetal morbidity and mortality. Mitral stenosis is the most common heart valve lesion in parturient and is almost always caused by rheumatic heart disease. Physiological changes that occur during pregnancy and the peripartum period can worsen symptoms and the degree of the heart disease. As a result, many women are first diagnosed with heart disease during pregnancy. Twenty four year old woman gravida 32-33 weeks with congestive heart failure class III, severe mitral stenosis, EF 59\%, moderate tricuspid regurgitation, and left atrial dilatation undergoing cesarean section with low-dose spinal anesthesia using bupivacaine $0,5 \%$ hyperbaric $7.5 \mathrm{mg}$ plus fentanyl $50 \mathrm{mcg}$ intrathecally. Sensory blocks were reached as high as thoracic 6th in 4 minutes and 20 seconds. The patient's hemodynamics are stable during both surgery and post surgery. Vasopressors were not needed. After surgery the patient was transferred to ICU for 3 days with stable hemodynamics. This report highlights that low-dose spinal anesthesia can be a good choice in the management of anesthesia for cesarean section accompanied by severe mitral stenosis.
\end{abstract}

Key words: severe mitral stenosis, low dose spinal anesthesia; cesarean section 


\section{Pendahuluan}

Kelainan jantung pada kehamilan masih menjadi faktor utama penyebab morbiditas dan mortalitas pada ibu. Angka kejadian penyakit jantung pada kehamilan di negara berkembang berkisar dari 0,2 hingga 3\%. ${ }^{1}$ Mitral stenosis adalah kelainan yang paling umum terjadi berkaitan dengan penyakit demam rematik. ${ }^{2}$ Data mengenai angka kejadian dan prevalensi mitral stenosis di Indonesia belum ada, akan tetapi berdasarkan penelitian, Indonesia termasuk wilayah Asia (ASEAN, tidak termasuk Jepang dan Cina) memiliki prevalensi 0,8 per $1000 .^{3}$ Angka kematian pada stenosis mitral ringan sebesar $1 \%$ dan $5-15 \%$ pada mitral stenosis berat. ${ }^{4}$ Wanita hamil dengan penyakit jantung merupakan masalah unik untuk dokter kandungan dan ahli anestesi.

Keparahan lesi dan status hemodinamik pasien sangat penting dalam manajemen anestesi untuk kelahiran sesar pada pasien ini. Manajemen anestesi bisa menantang dan sangat berisiko serta membutuhkan pemahaman yang menyeluruh tentang dampak dari kehamilan pada respon hemodinamik terhadap lesi jantung pasien. ${ }^{5}$ Anestesi spinal adalah teknik yang paling sering digunakan untuk tindakan sesar. Teknik konvensional sering disertai oleh efek samping seperti hipotensi, mual dan muntah. ${ }^{6}$ Hipotensi dapat membahayakan ibu dan bayi. Prinsip utama pembiusan pada pasien dengan mitral stenosis adalah dengan tujuan menghindari takikardia, menjaga kondisi irama sinus dan secara agresif mengatasi kejadian baru dari atrial fibrilasi baik farmakologis maupun dengan kardioversi terutama pada pasien dengan hemodinamik yang tidak baik, menghindari penurunan Systemic Vascular Resistance (SVR) yang akan menimbulkan kompensasi berupa peningkatan denyut jantung sehingga memperberat kerja jantung, menghindari hipovolemi dan kelebihan cairan, menghindari faktor yang dapat meningkatkan tekanan arteri pulmonal seperti hipoksia, maupun hiperkarbia. Teknik spinal anestesi dosis rendah pada beberapa penelitian dan laporan kasus memberikan hasil yang baik dalam menjaga hemodinamik yang stabil dan analgesia yang efektif. ${ }^{7}$

\section{Kasus}

Anamnesa

Pasien wanita usia 24 tahun (gravida 2, para 1) dengan usia kehamilan 32-33 minggu, Sejak 2 minggu sebelum masuk rumah sakit pasien mengeluhkan sesak nafas. Sesak dirasakan semakin memberat setiap hari. Pasien juga mengeluhkan sesaknya semakin memberat jika sedang beraktifitas dan membaik saat istirahat. Pasien telah mengetahui terdiagnosa penyakit jantung sejak 1 minggu yang lalu dan telah mendapatkan terapi furosemide $1 \times 20 \mathrm{mg}$ dan spinorolakton $1 \times 25 \mathrm{mg}$.

Pasien juga mengeluhkan alat kelaminnya membengkak sejak 1 bulan sebelumnya. Bengkak dirasakan semakin membesar, kemerahan, terasa nyeri terisi oleh cairan, cairan jernih dan tidak berbau. Pasien telah dilakukan tindakan insisi vulva di RSUD Mandau pada tanggal 25 Juli 2019, dan saat ini masih menunggu patologi anatomi. Pasien mengaku telah hamil 7 bulan dengan HPHT 12/12/18, Taksiran persalinan tanggal 19/10/19. Pasien telah melakukan Ante Natal Care (ANC) sebanyak 4x ke bidan dan 2x ke dokter spesialis kandungan di RSUD Mandau. Riwayat persalinan didapatkan bahwa anak pertama lahir pervaginam di bidan, aterm dengan berat 2900 gr. Pasien melakukan kontrasepsi dengan KB suntik per 3 bulan.

\section{Pemeriksaan Fisik}

Pada pemeriksaan fisik didapatkan data sebagai berikut:

$\begin{array}{ll}\text { Kesadaran } & \begin{array}{l}\text { Kompos mentis, } \\ \text { kooperatif } \\ 110 / 72 \mathrm{mmHg}\end{array} \\ \text { Tekanan darah } & 92 \mathrm{x} / \mathrm{menit} \\ \text { Nadi } & 22 \mathrm{x} / \text { menit } \\ \text { Pernafasan } & 36,5 \\ \text { Suhu } & 150 \mathrm{~cm} \\ \text { Tinggi Badan } & 48 \mathrm{~kg} \\ \text { Berat Badan } & 42 \mathrm{~kg} \\ \text { Berat Badan Sebelum } & \end{array}$

BMI

18,6 (normoweight) 
Kepala

normocephal, mata konjungtiva anemis $(-/-)$, sklera ikterik (-/-), edema palpebra (-/-)

Leher Pembesaran KGB (-)

Thorak

Abdomen

Genitalia

Ekstremitas perkusi : redup

Status Lokalis tra dan sinistra, pitting $(+)$

Akral hangat, $\mathrm{CRT}<2$ detik,
Jantung (Kardiomegali), inspeksi: Iktus kordis terlihat, palpasi: iktus kordis teraba, auskultasi: murmur diastolik (+). Paru, inspeksi: dada kanan-kiri simetris, palpasi: dada kanan-kiri sama, auskultasi: ronkhi $(+/+)$, wheezing $(-/-)$,

Edema pada labia mayor deksedem $(+/+)$ di ekstremitas bawah

\section{Pemeriksaan Penunjang}

Pemeriksaan darah

Pemeriksaan darah pada pasien ini dapat dilihat di tabel 1.

\section{Tabel 1. Hasil Pemeriksaan Darah}

\begin{tabular}{ll}
\hline Parameter & Nilai \\
Hemoglobin $(\mathrm{g} / \mathrm{dL})$ & 9,2 \\
Lekosit $(103 / \mathrm{uL})$ & 11,69 \\
Trombosit $(103 / \mathrm{uL}$ & 241 \\
Hematokrit $(106 / \mathrm{uL})$ & 29,4 \\
Albumin $(\mathrm{g} / \mathrm{dL})$ & 3,3 \\
PT $($ detik $)$ & 14,7 \\
APTT $($ detik) & 30,5 \\
INR & 1.11 \\
Ureum $(\mathrm{mg} / \mathrm{dl})$ & 34 \\
Creatinine $(\mathrm{mg} / \mathrm{dl})$ & 0,68 \\
HIV & negatif \\
\hline
\end{tabular}

\section{Pemeriksaan Ekokardiogram}

LA dilatasi, mitral kalsifikasi, EF 59\%, simpulan: MVA 0,5 cm2 (severe), TR Moderate

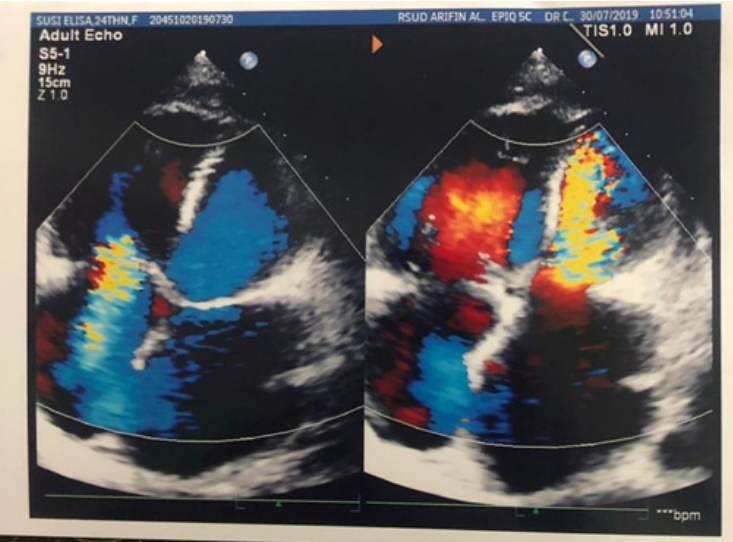

\section{Pemeriksaan Rontgen Thorax}

Dari pemeriksaan rontgen thorax didapatkan gambaran kardiomegali (Cardio Thoracic Ratio /CTR 60\%). Berdasarkan anamnesis, pemeriksaaan fisik dan penunjang, pasien dinilai sebagai ASA IV dengan gravida disertai mitral stenosis berat.

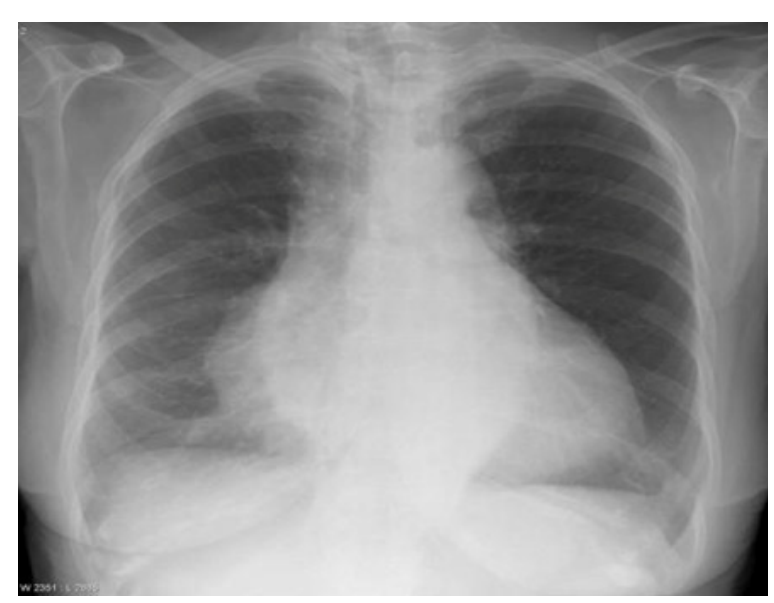

\section{Pengelolaan Anestesi}

Di dalam ruang operasi, dipasang monitor standar, didapatkan data dasar tekanan darah 109/73 $\mathrm{mmHg}$, denyut jantung $94 \mathrm{x} /$ menit, pernafasan $18 \mathrm{x} /$ menit, saturasi oksigen perifer 99\% dengan nasal kanul $2 \mathrm{~L} /$ menit. Pasien diberikan furosemide $40 \mathrm{mg}$ intravena. Pasien diposisikan left lateral kemudian dilakukan tindakan asepsis, 
Tabel 2. Monitoring selama Operasi

\begin{tabular}{l|l}
\hline Lama operasi (menit) & 45 \\
Level blok sensoris tertinggi & Torakal 6 \\
$\begin{array}{l}\text { Waktu untuk mencapai blok sensosris } \\
\text { tertinggi (detik) }\end{array}$ & 260 \\
$\begin{array}{l}\text { Waktu untuk mencapai Bromage } 2 \\
\text { (detik) }\end{array}$ & $90-102$ \\
APGAR skor menit ke-1 dan ke-5 & 7 dan 8 \\
Hipotensi/bradikardi & Tidak ada \\
Jumlah perdarahan (ml) & 200 \\
Jumlah produksi urin $(\mathrm{ml})$ & 400 \\
\hline
\end{tabular}

dengan jarum spinal Quinke 27G diinsersi secara midline melalui Tuffier's line. Bupivacaine $0,5 \%$ heavy sebanyak $7,5 \mathrm{mg}(1,5 \mathrm{ml})$ dengan adjuvan fentanyl 50 mcg dengan total volume 2,5 $\mathrm{ml}$ disuntikkan ke dalam ruang sub arakhnoid, kemudian pasien diposisikan supine segera setelah injeksi. Skor Bromage 3 dicapai dalam waktu 60-72 detik, Bromage 2 dalam 90-102 detik dan Bromage 1 dicapai dalam 135-180 detik setelah insersi. Ketinggian blok T6 tercapai dalam 4 menit 20 detik. Waktu insisi antara 5-10 menit. Hemodinamik setelah injeksi bupivakain dan fentanyl intratekal stabil. Fluktuasi hemodinamik sangat minimal dan sesuai dengan hemodinamik awal pasien. Saturasi oksigen pasien sebelum spinal 95-96\% dengan udara kamar dan selama operasi berlangsung pasien menggunakan nasal

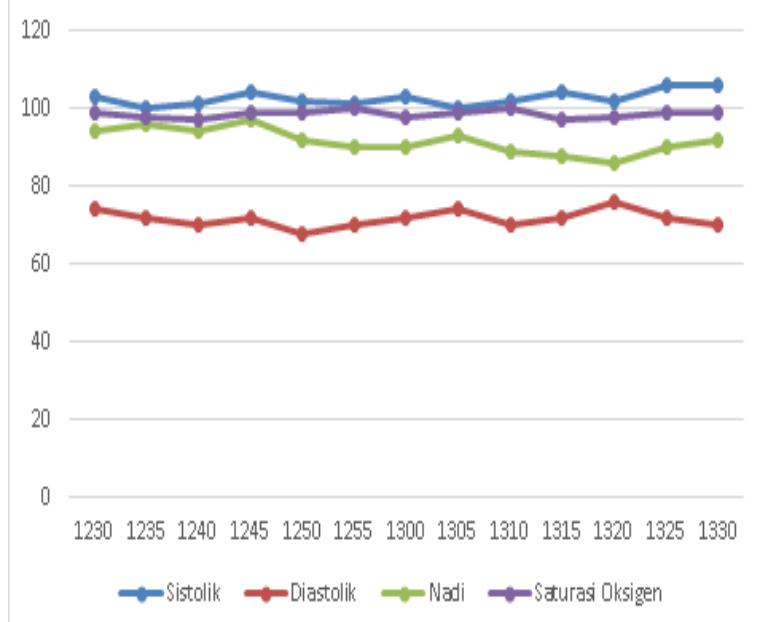

Grafik 1. Hemodinamik selama Operasi kanul 2 L/menit dan saturasi 99-100\%. Kenaikan nadi setelah bayi lahir disebabkan oleh pemberian oksitosin. Selama operasi dan pasca operasi tidak didapatkan keluhan sesak nafas, mual, muntah, pusing serta tidak terjadi hipotensi sehingga tidak digunakan obat-obatan untuk menaikan tekanan darah. Skor APGAR bayi 7 pada menit pertama dan 8 pada menit kelima.

Berat badan bayi 1600 gram dan dilakukan perawatan di ruang Neonatal Intensive Care Unit (NICU) untuk penanganan selanjutnya. Operasi berlangsung 45 menit dengan jumlah perdarahan sekitar $200 \mathrm{ml}$ dan produksi urin $400 \mathrm{ml}$. Selama operasi, pasien mendapatkan cairan kristaloid (Ringer Laktat) $500 \mathrm{ml}$ dan koloid (Gelofusine) $200 \mathrm{ml}$. Hemodinamik pasien dapat dilihat pada tabel 2 dan grafik 1.

\section{Pengelolaan Pascabedah}

Pasien dirawat di ruang ICU dengan obat anti nyeri yang digunakan setelah operasi diberikan oxycodone $2 \mathrm{mg}$ intravena kemudian dilanjutkan $1 \mathrm{mg} / \mathrm{jam}$ dengan menggunakan syringe pump. Selama di ICU hemodinamik stabil sehingga hari ke-3 setelah operasi pasien dapat kembali ke ruangan biasa. Data dapat dilihat di grafik 2 .

Pada hari ke-4 pasien pindah ke ruang perawatan biasa dan pasien pulang dari rumah sakit pada hari ke-5 setelah operasi.

\section{Pembahasan}

Perubahan fisiologis dalam sistem kardiovaskular 


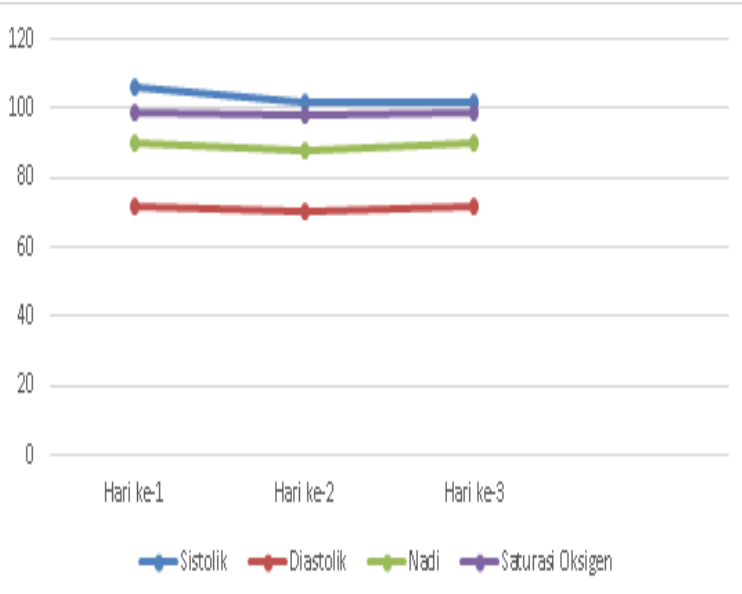

\section{Grafik 2. Hemodinamik Pasca Operasi}

dimulai pada trimester pertama, perubahan ini berlanjut pada trimester kedua dan ketiga. Ada peningkatan $40-50 \%$ di curah jantung, peningkatan $15-25 \%$ dalam denyut jantung, $45 \%$ peningkatan volume intravaskular dibandingkan nilai sebelum hamil. ${ }^{8,9}$ Perubahan kardiovaskular selama kehamilan dapat dilihat pada tabel 3.

Pada keadaan normal katup mitral mempunyai ukuran 4-6 $\mathrm{cm}^{2}$, bila area orifisium katup berkurang sampai $2 \mathrm{~cm}^{2}$, maka diperlukan upaya aktif atrium kiri berupa peningkatan tekanan

\section{Tabel 3. Perubahan Kardiovaskular selama} Kehamilan

\begin{tabular}{ll}
\hline Parameter & Perubahan \\
\hline Cardiac Output & $40-50 \%$ meningkat \\
Stroke volume & $30 \%$ meningkat \\
Heart rate & $15-25 \%$ meningkat \\
Intravaskular volume & $45 \%$ meningkat \\
Systemic Vascular Resis- & $20 \%$ menurun \\
tance & \\
Tekanan Darah Sistolik & Minimal \\
Tekanan Darah Diastolik & $20 \%$ menurun pada \\
& tengah kehamilan \\
Central Venous Pressure & Tidak berubah \\
Konsumsi O 2 & $30-40 \%$ meningkat \\
\hline
\end{tabular}

atrium kiri agar aliran transmitral yang normal dapat terjadi. Ini terjadi akibat adanya fibrosis dan fusi komisura katup mitral pada waktu fase penyembuhan demam reumatik. Stenosis mitral kritis terjadi bila pembukaan katup berkurang hingga menjadi $1 \mathrm{~cm}^{2}$. Pada tahap ini diperlukan suatu tekanan atrium kiri sebesar 25 mmHg untuk mempertahankan cardiac output yang normal. Peningkatan tekanan atrium kiri akan meningkatkan tekanan pada vena pulmonalis dan kapiler, sehingga bermanifestasi sebagai exertional dyspneu. Seiring dengan perkembangan penyakit, peningkatan tekanan atrium kiri kronis akan menyebabkan terjadinya hipertensi pulmonal, yang selanjutnya akan menyebabkan kenaikan tekanan dan volume akhir diastolik, regurgitasi trikuspid dan pulmonal sekunder dan seterusnya sebagai gagal jantung kanan dan kongesti sistemik. ${ }^{10}$

Hipertensi pulmonal merupakan komplikasi yang sering terjadi pada stenosis mitral. Pada awalnya hipertensi pulmonal terjadi secara pasif akibat kenaikan tekanan atrium kiri, terjadi perubahan pada vaskular paru berupa vasokonstriksi akibat endotelin atau perubahan anatomi yaitu remodelling akibat hipertrofi tunika media dan penebalan intima (reactive hypertension). ${ }^{10,11}$ Pelebaran progresif dari atrium kiri akan memicu dua komplikasi lanjut, yaitu pembentukan trombus mural yang terjadi pada sekitar $20 \%$ penderita, dan terjadinya atrial fibrilasi yang terjadi pada sekitar $40 \%$ penderita. Derajat mitral stenosis dapat dilihat di tabel 4 .

Prinsip utama pembiusan pada pasien dengan mitral stenosis adalah dengan tujuan menghindari takikardia, menjaga kondisi irama sinus dan secara agresif mengatasi kejadian baru dari atrial fibrilasi baik farmakologis maupun dengan kardioversi terutama pada pasien dengan hemodinamik yang tidak baik, menghindari penurunan SVR yang akan menimbulkan kompensasi berupa peningkatan denyut jantung sehingga memperberat kerja jantung, menghindari hipovolemi dan kelebihan cairan, menghindari faktor yang dapat meningkatkan tekanan arteri pulmonal seperti hipoksia, hiperkarbi maupun nyeri. $^{10,12}$

Penurunan SVR yang mendadak dapat diatasi dengan pemberian dosis kecil phenylephrine 
Tabel 4. Derajat Mitral Stenosis

\begin{tabular}{lllll}
\hline Pengukuran & Normal & Ringan & Sedang & Berat \\
\hline $\begin{array}{l}\text { Area katup mitral } \\
\text { (cm2) }\end{array}$ & $4.0-6.0$ & $1.5-2.5$ & $1.0-1.5$ & $<1.0$ \\
$\begin{array}{l}\text { Rerata gradien } \\
\text { tekanan (mmHg) }\end{array}$ & $<2$ & $2-6$ & $6-12$ & $>12$ \\
$\begin{array}{l}\text { Rerata tekanan arteri } \\
\text { pulmonalis (mmHg) }\end{array}$ & $10-20$ & $<30$ & $30-50$ & $>50$ \\
\hline
\end{tabular}

dan penambahan volume cairan bila diperlukan. Pemberian oksigen tambahan dengan monitoring pulsa oksimetri untuk mengurangi peningkatan PVR. Memposisikan pasien secara left uterine displacement juga merupakan suatu keharusan untuk menjaga aliran balik yang bagus. Selama kehamilan, wanita dengan penyakit jantung katup harus dievaluasi paling tidak sekali setiap trimester dan setiap kali ada perubahan gejala, untuk mengevaluasi setiap penurunan pada fungsi jantung ibu. ${ }^{13}$ Selama dua dekade terakhir, anestesi regional telah terbukti menjadi teknik yang aman pada pasien dengan kelainan jantung yang menjalani seksio sesarea. Epidural anestesi adalah pilihan yang menarik. Epidural anestesi lebih disukai pada pasien dengan mitral stenosis karena onset blok lambat karena itu hemodinamik lebih mudah dikendalikan. Efedrin profilaksis harus dihindari. Jika dibutuhkan vasopressor, obat pilihan dalam pasien dengan mitral stenosis adalah dosis rendah fenilefrin. Anestesi umum memiliki kerugian peningkatan tekanan arteri paru dan takikardia selama laringoskopi dan intubasi trakea. Ventilasi tekanan positif memiki dampak buruk pada aliran darah balik vena dan akhirnya dapat menyebabkan gagal jantung. Diluar dari kekurangan tersebut, jika anestesi umum dilakukan, maka obat yang dapat menyebabkan takikardia seperti sulfas atropin, ketamin, pancuronium dan meperidine, harus benar-benar dihindari. ${ }^{1,13,14}$

Teknik anestesi regional dipilih dengan pertimbangan kondisi klinis masih baik. Pasien masih bisa tidur terlentang dengan saturasi oksigen menggunakan udara ruangan 95-96\%. Dosis rendah bupivakain hiperbarik dikombinasikan dengan fentanyl menghasilkan blok yang adekuat dengan efek samping sistemik yang minimal berupa penurunan tahanan sistemik vaskular dan mencegah timbulnya hipotensi pada anestesi spinal. Dikarenakan aliran darah uterus tidak bersifat autoregulasi, maka perfusi uteroplasental berhubungan secara langsung dengan tekanan darah ibu. Karena itu penurunan tekanan darah ibu masih dapat ditoleransi oleh ibu tetapi tidak oleh janin. Salah satu strategi untuk mempertahankan hemodinamik yang stabil selama dilakukan spinal anestesi pada operasi sesar adalah dengan menggunakan bupivakain dosis rendah yang dikombinasikan dengan ajuvan opioid. Pada laporan kasus ini juga kami tidak menemukan adanya episode hipotensi dan desaturasi.

Anestesi lokal intratekal bekerja dengan menghambat voltage-gated sodium channels pada medula spinalis yang akan mempengaruhi impuls motorik dan sensorik dari serabut aferen dan eferen. Tingkat blok sensorik dan motorik ini tergantung pada teknik, agen dan dosis yang diberikan. Opioid yang diberikan ke ruang intratekal secara selektif akan menghasilkan efek analgesia dengan melalui interaksi dengan reseptor opioid di cornu dorsalis medula spinalis dan dengan demikian dapat meminimalkan dosis serta efek supraspinal dari lokal anestesi seperti hipotensi, depresi nafas, sedasi dan mual muntah. Lokasi utama dari reseptor opioid adalah pada substantia grisea dari substansia gelatinosa. Hal inilah yang menjadi dasar anatomi terjadinya selektif analgesia setelah opioid intratekal diberikan. ${ }^{15,16}$ Opioid intratekal secara selektif akan memblok transmisi stimulus dari serabut saraf $\mathrm{A}, \delta$ dan $\mathrm{C}$ afferent nociceptive dengan membentuk ikatan pada reseptor opioid di 
prasinaps dan pascasinaps. Pada pascasinaps, opioid akan meningkatkan konduksi ion kalium, meningkatkan hiperosmolaritas neuronneuron asendens tanpa membangkitkan efek somatosensorik maupun motorik. Efek prasinaps antara lain pelepasan adenosin spinal yang berperan penting sebagai mediator spesifik analgetik. ${ }^{15}$ Fentanyl bekerja secara sinergis dengan bupivakain dalam menurunkan ambang nyeri tanpa meningkatkan blokade simpatis dan motorik.

Telah banyak penelitian yang membuktikan efektifitas penggunaan opioid pada anestesi spinal terutama pada operasi sesar. Penelitian-penelitian sebelumnya membuktikan bahwa opioid lipofilik contohnya fentanyl dapat mempercepat awitan dan memperpanjang durasi blok bupivakain serta memperpanjang durasi analgesia pascaoperasi. Kombinasi keduanya memiliki kecepatan awitan 5 menit secara intratekal dan 10 menit melalui epidural dan secara relatif memiliki durasi aksi yang lebih pendek dikarenakan oleh adanya redistribusi (2-4 jam intratekal dan epidural). Tidak didapatkan adanya metabolit aktif dan memiliki sifat 800 kali lebih larut dalam lemak dibandingkan morfin. Dan karena kelarutan yang sangat tinggi dalam lemak sehingga secara cepat akan berikatan dengan reseptor opioid di kornu dorsalis medula spinalis, dan awitan yang cepat ini sangat menguntungkan baik sebagai analgesia pada persalinan normal maupun pada kasus operasi sesar emergensi. ${ }^{17}$

Sampai saat ini anestesi spinal pada pasien dengan stenosis mitral masih merupakan kontraindikasi. Pada pasien ini dilakukan anestesi spinal dengan memenuhi hal-hal yang harus diperhatikan pada anestesi dengan mitral stenosis yaitu menghindari takikardia, menjaga kondisi irama sinus dan secara agresif mengatasi kejadian baru dari atrial fibrilasi, menghindari penurunan SVR, menghindari hipovolemia dan kelebihan cairan serta menghindari faktor yang dapat meningkatkan tekanan arteri pulmonal. Penelitian sebelumnya menyimpulkan bahwa anestesi spinal dosis rendah tidak menyebabkan perubahan hemodinamik dan fentanyl sebagai adjuvan mempunyai efek memperpanjang analgesia dan blok motorik yang adekuat sehingga pada pasien ini kami lakukan pembiusan dengan anestesi spinal dosis rendah dan tidak ditemukan adanya kejadian hipotensi maupun perubahan hemodinamik yang lain.

\section{Simpulan}

Prinsip utama pembiusan pada pasien dengan mitral stenosis adalah menghindari takikardia, menjaga kondisi irama sinus dan secara agresif mengatasi kejadian baru dari atrial fibrilasi, menghindari penurunan SVR, menghindari hipovolemia dan kelebihan cairan serta menghindari faktor yang dapat meningkatkan tekanan arteri pulmonal. Pada pasien ini anestesi spinal dengan dosis rendah dapat digunakan sebagai alternatif pembiusan pada pasien dengan mitral stenosis karena hemodinamik yang stabil dibandingkan dengan spinal konvensional.

\section{Daftar Pustaka}

1. Weiner MM, Vahl TP, Kahn RA. Case scenario: cesarean section complicated by rheumatic mitral stenosis. Anesthesiology 2011; 114: 949-57.

2. Nataraj MS, Giri V. Anaesthetic management of caesarean section with mitral stenosis and respiratory tract infection. J Obstet Anaesth Crit Care. 2014; 4:78-80.

3. Carapetis JR, Steer AC, Mulholland EK, Weber M. The global burden of group A streptococcal diseases. Lancet Infect Dis. 2005; 5:685-94.

4. Westhoff BM, Hilfiker KD, Günter HH, Schieffer E, Drexler H. Management of heart diseases in pregnancy: rheumatic and congenital heart disease, myocardial infarction and post partum cardiomyopathy. Internist (Berl). 2008; 49: 805-10.

5. Gai B, Abuja V, Kumar M. Low dose combined spinal and epidural anaesthesia in a parturient with severe mitral stenosis and severe pulmonary arterial hypertension for caesarean section. Southern African Journal 
of Anaesthesia and Analgesia. 2009; 15:3, $27-28$.

6. Sunko BM. Low dose spinal versus epidural anaesthesia for delivery and expected caesar section. Per Biol. 2011; 113:2, 275-77.

7. Parneix M, Fanoul M, Colson P. Lowdose combined spinal-epidural anaesthesia for caesarean section in a patient with Eisenmenger's syndrome. Int J Obst Anest. 2009; 18: 81-84.

8. Grindheim G, Estensen ME, Langesaeter $\mathrm{E}$, Rosseland LA, Toska K. Changes in blood pressure during healthy pregnancy: A longitudinal cohort study. J Hypertens. 2012; $30: 2,42-50$.

9. Hensley FA, Martin DE, Gravlee GP. A practical approach to cardiac anesthesia 5th, edition. Philadelphia: Lippincott William and Wilkins; 2013: 337-41.

10. Isngadi, Isngadi, Rafidya IS. Manajemen anestesi pada kehamilan dengan penyakit jantung. Malang: Departemen Anestesiologi dan Terapi Intensif FKUB RSUD Dr. Saiful Anwar. 2017: 78.

11. Butterwort JF, Mackey DC, Wasnick JD. Morgan and Mikhail's Clinical Anesthesiology. USA: The McGraw Hill companies; 2013: 827-28.
12. Karim ME, Akhter S, Yasin MM. Anaesthetic challenge in undiagnosed mitral valvular disease in emergency lower segment caesarean section in a secondary level hospital-case report. JAFMC Bangladesh. 2013; 9:1.

13. Hartono R, Isngadi, Husodo DP. Anestesi spinal dosis rendah untuk pasien operasi sesar dengan mitral stenosis berat. JAI (Jurnal Anestesiologi Indonesia). 2018; 10:2, 163-74.

14. Kocum A, Sener M, Calıskan E, Izmirli H, Tarım E, Kocum T. Epidural anesthesia for cesarean section in a patient with severe mitral stenosis and pulmonary hypertension. J Cardiothorac Vasc Anesth. 2010; 24:1022-23.

15. Pardo CM, Miller RD. Basic of Anesthesia, 7th edition, Philadelphia: Elsevier; 2018: 554-56.

16. Goldszmidt E, Macarthur A, Silversides C. Anesthetic management of a consecutive cohort of women with heart disease for labor and delivery. Int J Obstet Anesth. 2010; 19:266.

17. Kannan M, Vijayanand G. Mitral stenosis andp pregnancy: current concepts in anesthetic practice. Indian Journal of Anethesia. 2010; 10:2, 439-44. 